\title{
Surface Modification through Biocompatible Coatings of Tricalcium Phosphate on Magnesium to Obtain Uniform Degradation Behaviour
}

\author{
W. Aperador ${ }^{1, *}$, A. Delgado ${ }^{1}$, J. C. Caicedo ${ }^{2}$ \\ ${ }^{1}$ School of Engineering, Universidad Militar Nueva Granada, Bogotá-Colombia \\ 2 Tribology Polymers, Powder Metallurgy and Processing of Solid Recycled Research Group \\ Universidad del Valle, Cali - Colombia \\ *E-mail: g.ing.materiales@gmail.com
}

doi: $10.20964 / 2017.09 .59$

Received: 19 April 2017 / Accepted: 19 July 2017 / Published: 13 August 2017

In this work, the surface of a Mg-8Er alloy was modified by coating with tricalcium phosphate via electrochemical deposition to make the alloy more resistant to corrosion by body fluids. The goal is to improve the integration of implants, avoid the rejection of cytotoxic products, and optimize bone regeneration. The morphologies of the substrate and the coating were examined using X-ray diffraction (XRD). Corrosion tests were performed using potentiodynamic polarization techniques and electrochemical impedance spectroscopy (EIS) under conditions similar to those of the human body, which in this case is an aqueous solution of oxygen and various salts, such as sodium chloride $(\mathrm{NaCl})$, magnesium chloride $(\mathrm{MgCl})$, potassium chloride $(\mathrm{KCl})$ and glucose. The solution had an overall $\mathrm{pH}$ of approximately 7.4. The immersion test results show that the calcium phosphate coating can mitigate the corrosion of the $\mathrm{Mg}$ alloy (substrate). Scanning electron microscopy (SEM) revealed that the tricalcium phosphate coating can mitigate the general corrosion of the $\mathrm{Mg}-8 \mathrm{Er}$ alloy.

Keywords: Magnesium, biocompatibility, corrosion, tricalcium phosphate, coating.

\section{$\underline{\text { FULL TEXT }}$}

(C) 2017 The Authors. Published by ESG (www.electrochemsci.org). This article is an open access article distributed under the terms and conditions of the Creative Commons Attribution license (http://creativecommons.org/licenses/by/4.0/). 